\title{
Feasibility Study on Discrimination of Neo-plastic and Non-Neoplastic Gastric Tissues Using Spark Discharge Assisted Laser Induced Breakdown Spectroscopy
}

\author{
Aida Seifalinezhad' ${ }^{1}$, Maryam Bahreini' ${ }^{2,3^{*}}$, Mohammad Mahdi Hassani Matin', Seyed Hassan Tavassoli' \\ ${ }^{1}$ Laser and Plasma Research Institute, Shahid Beheshti University, G. C., Tehran, Iran \\ ${ }^{2}$ Laser Application in Medical Sciences Research Center (LAMSRC), Shahid Beheshti University of Medical Sciences, \\ Tehran, Iran \\ ${ }^{3}$ Hazrat-e Masoumeh University, Qom, Iran
}

\section{*Correspondence to \\ Maryam Bahreini, Laser \\ Application in Medical Sciences Research Center (LAMSRC), \\ Shahid Beheshti University of \\ Medical Sciences, Tehran, Iran. \\ Tel: +982122749221 ; \\ Fax: +982122718021 ; \\ Email: Bahreini_mm@yahoo.com}

Published online 15 December 2018

\begin{abstract}
Introduction: The present work is a novel in vitro study that evaluated the possibility of diagnosing neoplastic from nonneoplastic gastric tissues using spark discharge assisted laser induced breakdown spectroscopy (SD-LIBS) method.

Methods: In these experiments, the low energy laser pulses ablated a tiny amount of tissue surface leading to plasma formation. Then, a spark discharge was applied to plasma in order to intensify the plasma radiation. Light emission from plasma was recorded as spectra which were analyzed. Gastric tissues of 5 people were studied through this method.

Results: The SD-LIBS technique had the potential to discriminate normal and cancerous tissues based on the significant differences in the intensities of some particular elements. The comparison of normalized calcium $(\mathrm{Ca})$ and magnesium $(\mathrm{Mg})$ peaks of neoplastic and nonneoplastic gastric tissues could be viewed as a practical measure for tissue discrimination since Ca and Mg peaks in spectra of neoplastic were noticeably higher than nonneoplastic.

Conclusion: Considering the identification of gastric cancer, the applied method in these experiments seems quite fast, noninvasive and cost-effective with respect to other conventional methods. The significant increment of specific Ca and Mg lines of neoplastic gastric tissues in comparison to the nonneoplastic ones can be considered as valuable information that might bring about tissue classification. The number of samples in this work, however, was not sufficient for a decisive conclusion and further researches is needed to generalize this idea.

Keywords: Gastric; Laser; Neo-plastic; Spectroscopy; Tissue.
\end{abstract}

\begin{abstract}
Introduction
Cancer is the second most common reason of death after cardiovascular diseases in many countries. Currently, early diagnosis and improved evaluating methods help a large number of cancer patients prolonging their lives. ${ }^{1}$ One of the most widespread cancers is stomach cancer also known as gastric cancer. Gastric cancer is the fifth most typical malignancy in the world and the third leading cause of death from cancer in people. ${ }^{2}$

The methods used for detection of different kinds of cancer, nowadays are time-consuming and demand a biopsy procedure. Since optical methods carry numerous merits, they are more commonly applied in various areas ${ }^{3}$ including medical diagnosis. ${ }^{4}$ Over the past decades,
\end{abstract}

a range of spectroscopic methods has been acquired frequently for detection of cancer, ${ }^{5}$ including Raman spectroscopy ${ }^{6}$ fluorescence spectroscopy ${ }^{7,8}$ and laser induced breakdown spectroscopy (LIBS) techniques. ${ }^{9,10}$ LIBS technique is an analytic method based on atomic emissions from a sample. In this method, the laser is focused onto a tiny area of the sample surface. The laser beam ablates a very tiny amount of sample, from nanograms to picograms, which, indeed, form a plasma plume. Emissions of excited atoms, ions, and molecules in this plasma are recorded as a spectrum and analyzed for atomic identification of the sample. In recent years, this technique is mostly used for analysis of different tissues, including hard tissues such as hair, ${ }^{11}$ nails ${ }^{12-18}$ and 
teeth ${ }^{19-22}$ and soft tissues such as blood, ${ }^{23}$ cervical, ${ }^{24}$ liver $^{25}$ and colorectal tissues. ${ }^{26}$ What sets this method apart from other conventional methods is the convenience of sample preparation, higher speed of performance and no direct connection with samples especially contaminant materials. ${ }^{27,28}$

It is good to notice that in LIBS method, in low energies of laser pulses, the obtained signal to noise ratio $(\mathrm{S} / \mathrm{N})$ could not be viewed as good. At high laser pulse energies, on the other hand, the tissue could get destroyed completely after some laser pulses. The S/N can be improved by using low energy of laser in LIBS combined with spark discharge technique which is called spark discharge assisted laser induced breakdown spectroscopy (SD-LIBS). ${ }^{29}$ This method is first introduced by Breach and Cross in 1962 after the invention of the laser. This practical method can extensively be acquired in a range of areas. It is also simple and inexpensive that only necessitates a simple power supply. ${ }^{30,31}$

In the above-mentioned method, the spark is created on the plasma which has been generated through the LIBS technique. Therefore a significant increment in the intensity of the spectra with less tissue ablation can be experienced. This method can be considered as an invasive technique through which quality spectra can be detected. ${ }^{29}$

In this research, for the first time, the SD-LIBS technique is applied for comparing the spectra of neoplastic and nonneoplastic gastric tissues and finding the distinction between their emission spectra. The present work focuses on an in vitro study to compare the elemental concentrations of different tissues.

\section{Methods}

In this section the tissue samples and experimental setup used for this study are explained.

\section{Tissue Samples}

Prior to carrying out experiments, the biopsy procedure was performed to obtain thirty surgical specimens of gastric cancer from 5 people, belonging to three men and 2 women in Imam Khomeini Hospital. Preparation of each sample took almost 4 days and the experiments were carried a day after sample preparation. The cuttings of nonneoplastic tissues of the same person were made at approximately $1 \mathrm{~cm}$ far from the massively evident tumor margin to minimize the possibility of involving the carcinoma. Each tissue was doubled in order to allow for pathological analysis to be done in parallel to the SD-LIBS analysis.

The naturally soft texture and rough surfaces of gastric tissues gave rise to some difficulties during the performance of the experiments, including frequent setup alignment to acquire the ideal possible spectrum of each spot. To avoid such issues, these tissues had been processed through some steps to become hard enough

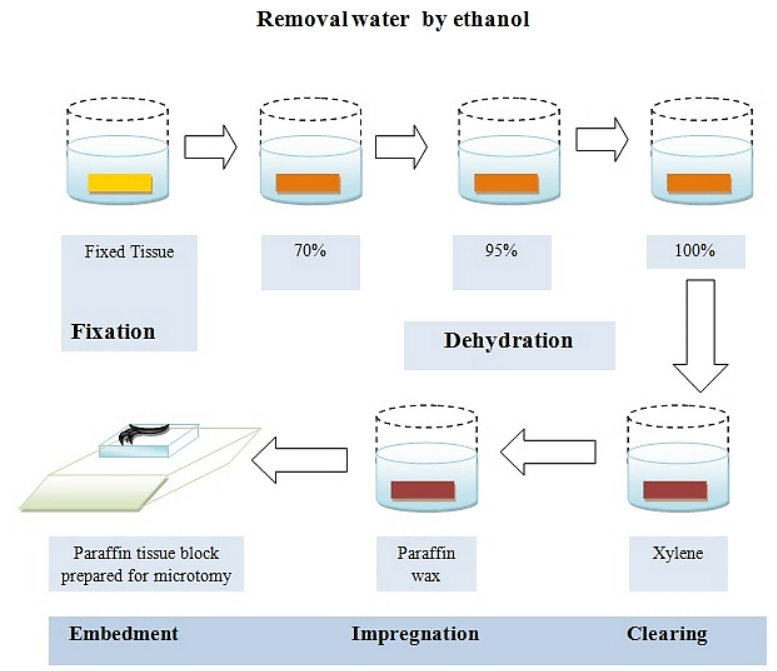

Figure 1. Sample Preparation Steps.

to be sectioned and then analyzed through SD-LIBS technique. The related processes are shown in Figure 1. Regularly, this process is performed by infiltrating and tissue embedding with paraffin wax. In this procedure water removal was essential since water and paraffin were not solvable. The whole steps are as shown below:

1. Fixation: preserve the cell morphology and detail. A fixative brings about the cross linking of proteins to convert them into a state where the tissue detail and information is fixed.

2. Dehydration: In this step water removal from the tissue is done by passing the tissue in $70 \%$ to $100 \%$ alcohol.

2. Clearing: xylene which is miscible with both paraffin and alcohol is used to clear the alcohol.

3. Impregnation: Subsequently, tissues are placed in melted paraffin wax.

4. Embedment: Tissues which are still in molten paraffin and are kept in the cassettes are manually put into the embedding molds. The embedding mold is then put on a refrigerated surface to allow the paraffin to solidify. Once the paraffin is solid, the entire block with the cassette is popped out of the mold and is ready for thin sectioning using microtome. The prepared tissues are cut into $10 \times 10$ $\mathrm{mm}^{2}$ sections with $2 \mathrm{~mm}$ of thickness using a microtome. At last the samples are set on the glass slides.

Five patients are studied during this research. Both neoplastic and nonneoplastic samples are taken from 3 different parts of each patient's gastric tissue. For each person, three samples of normal tissue and three samples of cancerous tissue are taken for further experiments.

\section{Experimental Setup}

The SD-LIBS setup used in the present work for experimental measurements is depicted in Figure 2.

A Q-Switched Nd: YAG laser (Continuum, Surelite III) was used working at a wavelength of $1064 \mathrm{~nm}$ to generate plasma from the sample surface. The laser pulse energy 


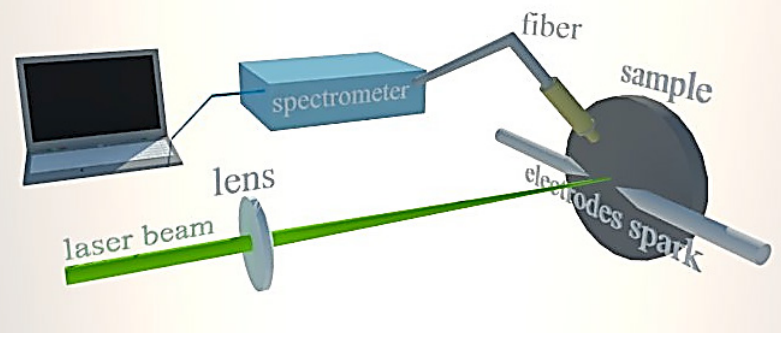

Figure 2. The Experimental Setup.

for the experiments was $30 \mathrm{~mJ}$ per pulse with a repetition rate of $1 \mathrm{~Hz}$ and pulse duration of $6 \mathrm{~ns}$. A gate width of $20 \mu \mathrm{s}$ and optimum delay time of $1 \mu \mathrm{s}$ were acquired in the experiments. The laser beam was focused on the sample through a $17 \mathrm{~cm}$ focal length planoconvex lens in order to create a breakdown on the sample surface. The plasma was produced between 2 electrodes which were in $6 \mathrm{~mm}$ distance of each other and are placed $1.5 \mathrm{~mm}$ away from the surface of the sample. The spark was created on the induced plasma. So the plasma temperature was increased and the signals were enhanced greatly. The emission of the plasma was collected using a $1 \mathrm{~m}$ long fused-silica optical fiber, which was $17 \mathrm{~mm}$ far from the sample surface with an angle of 45 and then transferred to the Echelle spectrometer (Kestrel, SE200).

The spectrometer was coupled to an intensified charge coupled device (ICCD) camera (Andor, iStar DH734). The system was monitored by Kestrel-Spec ${ }^{\circledR}$ software to acquire images from the assisted camera. The specimens moved in 3 directions through an $\mathrm{x}-\mathrm{y}-\mathrm{z}$ holder.

\section{Result and Discussion}

\section{Elemental Analysis of Tissue}

All tissues (neoplastic and non-neoplastic gastric tissue belonged to 5 patients) were analyzed in the above mentioned setup. Each SD-LIBS spectrum was the average of 3 spectra derived from 3 different parts of each tissue. As an example the spectrum of a nonneoplastic gastric tissue is displayed in Figure 3.

The spectra obtained from neoplastic and nonneoplastic gastric tissues were almost the same as both types had

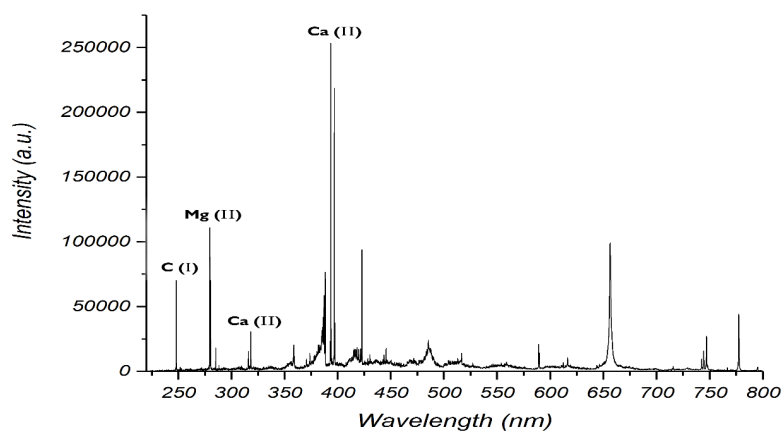

Figure 3. A Spectrum of Non-neoplastic Gastric Tissue.

the same lines of elements. Several elements have been detected in the spectrum of gastric tissue, such as: calcium $(\mathrm{Ca})$, magnesium $(\mathrm{Mg})$, potassium, sodium, iron, titanium, carbon, oxygen and nitrogen. What sets the spectra of normal and cancerous tissues apart were their significant intensity difference of special elements.

SD-LIBS method, On the other hand, had some advantages over LIBS method. At low energies of laser, better spectrum with higher line intensities could be obtained through SD-LIBS technique in comparison to LIBS technique. Therefore the tissue damage in low energies of laser was lesser. A significant increase in the ratio of signal to noise in the obtained emission spectra was clearly detectable as well. More elements also could be detected through the SD-LIBS method in lower energies of laser. What is more, the optical emission of plasma generated through SD-LIBS technique lasted up to several milliseconds which was much longer than the plasma created through LIBS method ( $\mu$ s range).

Elemental Comparison of Neoplastic and Non-neoplastic Gastric Tissues

For each person, 3 samples of normal tissue and 3 samples of cancerous tissue were taken for further experiments. Thus, the results were based on thirty samples belonged to 5 patients. The histograms illustrate the average emission intensities of each element for the neoplastic and nonneoplastic gastric tissues are shown in Figure 4 and Figure 5. The signal analyzing was done by calculating

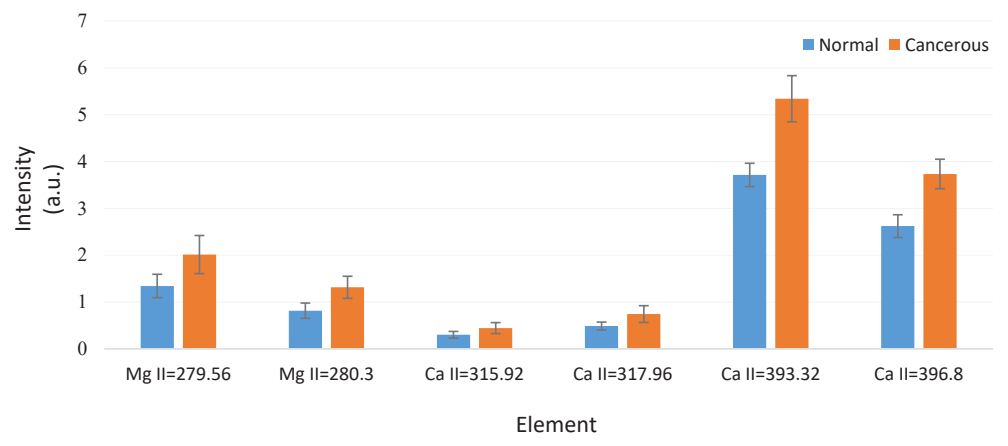

Figure 4. Histogram Comparing the Average Normalized Intensities of 6 Elemental Lines Obtained From Both Neoplastic (Orange) and Nonneoplastic (Blue) Gastric Tissues of 5 Patients. 


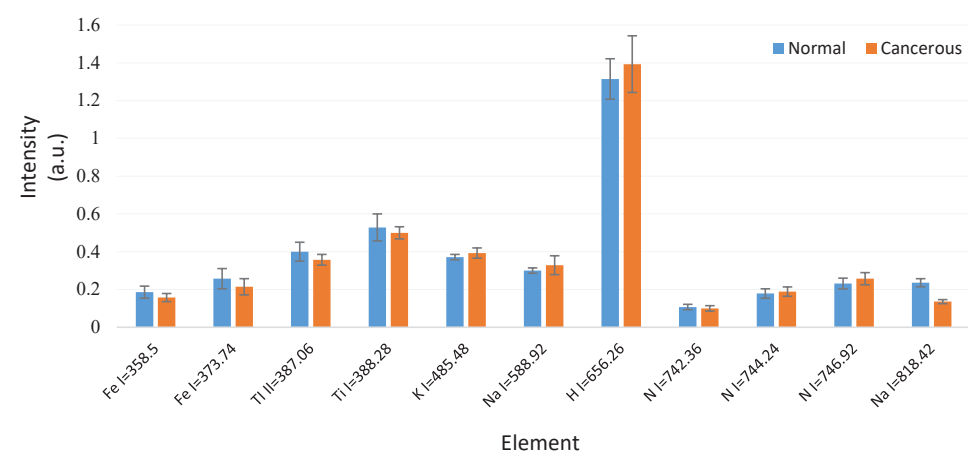

Figure 5. Histogram Comparing the Average Normalized Intensities of 11 Elemental Lines Obtained From Both Neoplastic (Orange) and Nonneoplastic (Blue) Gastric Tissues of 5 Patients.

the area under each peak. In this analysis, the intensities of every element were normalized to the intensity of the carbon spectral line at $247.8 \mathrm{~nm}$ to avoid any experimental fluctuations and matrix interference effects. This carbon line was selected mostly because it was independent of the status of the samples. Consequently, it seemed reasonable to reference carbon as a line with the intensity of one and normalize other elements to this element. In this case, the comparison could be considered more accurate..$^{32,33}$

Comparison between the elements of both tissue types revealed that the intensity of the $\mathrm{Ca}$ and $\mathrm{Mg}$ lines in all neoplastic tissue samples was noticeably higher than the intensity of the identical lines in nonneoplastic tissues. Since the intensity differences in these 2 elements were more than the experiment error bars, the differences in $\mathrm{Ca}$ and $\mathrm{Mg}$ elements were statistically significant. The emission lines at $315.92 \mathrm{~nm}, 317.96 \mathrm{~nm}, 393.32 \mathrm{~nm}$ and $396.8 \mathrm{~nm}$ for $\mathrm{Ca}$, and the emission lines at $279.56 \mathrm{~nm}$ and $280.3 \mathrm{~nm}$ for $\mathrm{Mg}$ were chosen. These lines were selected since they were free of intercession with other lines and well resolved, had higher intensities among other related lines and subject very little to self-absorption. ${ }^{34}$

For a better comparison, the average spectra of both neoplastic and nonneoplastic over the chosen $\mathrm{Ca}$ and $\mathrm{Mg}$ lines are demonstrated in Figure 6. Obviously, the average intensity of neoplastic spectra for the selected $\mathrm{Ca}$ and $\mathrm{Mg}$ lines is higher than the nonneoplastic ones. As a result, the increment in the emission intensities of $\mathrm{Ca}$ and $\mathrm{Mg}$ lines in cancerous tissues in comparison to normal ones could be regarded as a good indicator of neoplastic tissue. Over the last decades, similar differences in the intensities of some elements were also associated with different diseases. Kumar et al recognized in their study on dog's liver that the $\mathrm{Ca}, \mathrm{Al}$, and $\mathrm{Mg}$ intensities were stronger for malignant tissue cells than normal ones. ${ }^{35}$ In addition, Imam et al used LIBS technique and showed that there is an enhancement in the concentration levels of specific elements, including $\mathrm{Ca}, \mathrm{Zn}, \mathrm{Cu}, \mathrm{Mn}$ and $\mathrm{Fe}$ in the cancerous breast tissues in comparison to the normal ones. ${ }^{32}$ Another study on breast and colorectal cancer was done by A. El-Hussein et al showed a dramatic increase in the intensities of the normalized spectral lines of $\mathrm{Ca}$ and $\mathrm{Mg}$ in neoplastic tissues in comparison to nonneoplastic ones in both cancer types. ${ }^{26}$ Moreover, in the research performed by EL Sherbini et al through the LIBS method, the intensities of some elements, including $\mathrm{Mg}, \mathrm{K}, \mathrm{Ca}, \mathrm{Na}$, $\mathrm{Fe}, \mathrm{Mn}$ and $\mathrm{Cu}$ in malignant liver tissues in comparison to normal ones experienced a dramaticelevation. ${ }^{36}$

Using atomic absorption spectrometry (AAS) technique, Nasiadek et al examined the $\mathrm{Ca}, \mathrm{Mg}, \mathrm{Zn}, \mathrm{Fe}, \mathrm{Cd}$ and $\mathrm{Cu}$ concentrations in uterine myoma and uterine cancer. They discovered a remarkable $\mathrm{Ca}^{2+}$ as well as the $\mathrm{Mg}$ level increase in uterine cancer tissues in comparison to normal uterine tissues. Moreover, they detected a notable increase of $\mathrm{Mg}$ and $\mathrm{Mg} / \mathrm{Ca}$ ratio in uterine myoma. ${ }^{37,38}$ Furthermore, the development of cancer can be attributed to Ca element based on Harvard School of Public Health research in 1998. This study revealed that the risk of being identified with metastasis prostate in those men
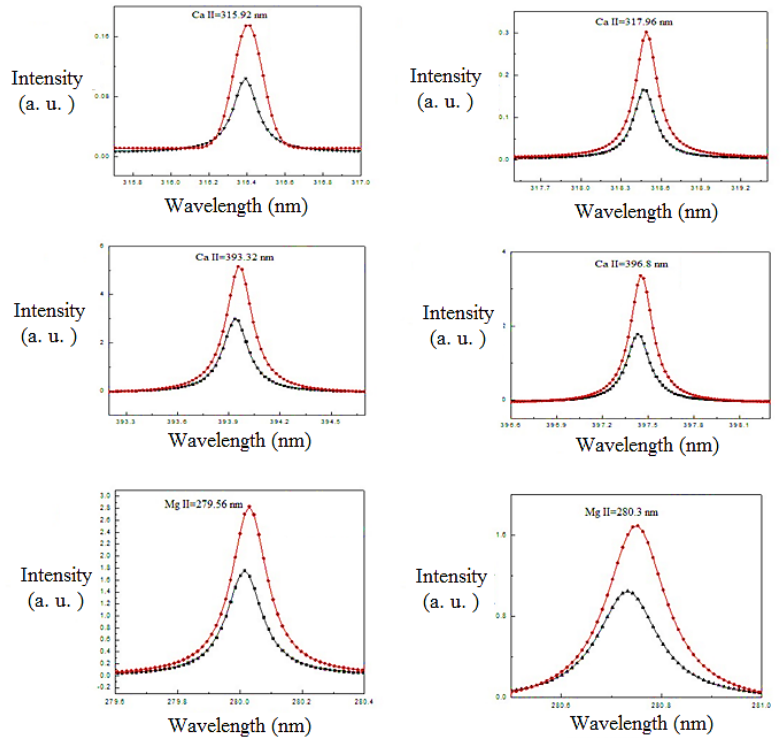

Figure 6. Comparing the Average Normalized Intensities of (a)-(d) $\mathrm{Ca}$ and (e)-(f) Mg Lines for Neoplastic (Red) And Nonneoplastic (Black) Gastric Tissues. 
consuming from $1500 \mathrm{mg}$ to $1999 \mathrm{mg}$ of Ca per day is double compared to those taking $500 \mathrm{mg}$ a day or less. ${ }^{39}$ The risk of developing metastatic prostate cancer for those consuming $2000 \mathrm{mg}$ or more is over four times in the same comparison. According to the results obtained with other researches, any disturbance in the intensities of $\mathrm{Ca}$ lines in tissues can give some information about tissue condition. ${ }^{39}$ In fact, people suffering from a cancer disease face hypercalcemia in 2 ways: (1) When a tumor develops in the bone and then it ruins bony tissue. (2) When elements secreted by cancer cells can increase Ca levels and the bone is not involved. ${ }^{40}$ These 2 mechanisms work simultaneously. Since it has been proven that the state of not moving enough leads to a rise in the amounts of $\mathrm{Ca}$ the bone loses, it is more likely that cancer patients who mostly stay in bed become vulnerable to hypercalcemia. These patients also consume deficient amounts of food and liquids and are regularly dehydrated. Dehydration diminishes kidneys' capability to eliminate extra $\mathrm{Ca}$ from the body. On the other hand, the amount of liquid liberated from the body can be elevated by hormones and diuretics which bring about hypercalcemia. ${ }^{41}$ Therefore, the rise in the intensity of $\mathrm{Ca}$ line can be associated with the existence of cancer.

In this study, a notable increment in the intensities of the selected spectral lines of $\mathrm{Mg}$ element in the neoplastic samples in comparison to the normal ones was clearly shown. This rise could be explained by the principal role of $\mathrm{Mg}$ in the biosynthesis of proteins which plays a key role in cells multiplying intensity. It was proven that cancer disease disturbs $\mathrm{Mg}$ distribution. These disturbances lead to reduction of $\mathrm{Mg}$ in nonneoplastic tissues and transference of this element through blood cells. This shows why malignant tissues demand this element. ${ }^{42}$ Studies that were conducted by Kohli et al and Tansy and Kendall showed that for patients who were subjected to radiotherapy or chemotherapy, the level of $\mathrm{Mg}$ in their bodies comes back to normal. ${ }^{43,44}$ This research approves that $\mathrm{Mg}$ plays an important role in tissue metabolism. Increment in concentration of $\mathrm{Mg}$ is hence a further, critical factor which is valuable and helpful in the estimation of tumor development.

\section{Conclusion}

In this research SD-LIBS method was applied to discriminate between neoplastic and nonneoplastic gastric tissues. The SD-LIBS method in comparison to other conventional techniques bears more merits, including less tissue damage, higher speed of performance and effective cost. The spectra obtained from normal and cancerous tissues through SD-LIBS method provided valuable information for further studies. Based on these experiments, in cancerous spectra the intensities of specific $\mathrm{Ca}$ and $\mathrm{Mg}$ lines experience an increase in comparison to normal spectra obtained from the same person. This survey result is consistent with results from previous reports. Regarding stomach cancer diagnosis, it is logical to argue that higher peaks of specific $\mathrm{Ca}$ and $\mathrm{Mg}$ lines in a part of a gastric tissue in comparison to the related normal tissue are associated with the existence of cancer. The number of samples in this work, however, was not sufficient for decisive conclusion and further researches is needed to generalize this idea. Moreover, SD-LIBS method should become simpler for future in vivo study.

\section{Ethical Considerations}

All experiments in this research were carried out according to the protocols approved by the ethical committee of Shahid Beheshti University of Medical Sciences.

\section{Conflict of Interests}

The authors declare no conflict of interest.

\section{Acknowledgment}

The authors would like to thank Dr. Nader Emami Razavi for their kind help in collecting and perpetrating tissue samples.

\section{References}

1. Sudhakar A. History of Cancer, Ancient and Modern Treatment Methods. J Cancer Sci Ther. 2009;1(2):1-4. doi:10.4172/1948-5956.100000e2

2. Zali H, Rezaei-Tavirani M, Azodi M. Gastric cancer: prevention, risk factors and treatment. Gastroenterol Hepatol Bed Bench. 2011;4(4):175-185.

3. Bahreini M. The effect of substrate on electric field enhancement of tip-enhanced Raman spectroscopy (TERS). AIP Conf Proc. 2018;1920(1):020013. doi:10.1063/1.5018945

4. Singh VK, Rai AK. Prospects for laser-induced breakdown spectroscopy for biomedical applications: a review. Lasers Med Sci. 2011;26(5):673-687. doi:10.1007/s10103-011-09212

5. Bahreini M. Role of optical spectroscopic methods in neurooncological sciences. J Lasers Med Sci. 2015;6(2):51-61.

6. Matousek P, Stone N. Prospects for the diagnosis of breast cancer by noninvasive probing of calcifications using transmission Raman spectroscopy. J Biomed Opt. 2007;12(2):024008. doi:10.1117/1.2718934

7. Izuishi $\mathrm{K}$, Tajiri $\mathrm{H}$, Fujii $\mathrm{T}$, et al. The histological basis of detection of adenoma and cancer in the colon by autofluorescence endoscopic imaging. Endoscopy. 1999;31(7):511-516. doi:10.1055/s-1999-57

8. Bottiroli G, Croce AC, Locatelli D, et al. Natural fluorescence of normal and neoplastic human colon: a comprehensive "ex vivo" study. Lasers Surg Med. 1995;16(1):48-60.

9. Singh S, Badaya S. Laser induced breakdown spectroscopy (LIBS) in cervical cancer screening: a proposed tool. N Indian J Surg. 2011;2:299.

10. Liehr JG, Jones JS. Role of iron in estrogen-induced cancer. Curr Med Chem. 2001;8(7):839-849.

11. Vahid Dastjerdi M, Derakhshan Zadeh Z, Mousavi SJ, Ranjbar Askari H, Soltanolkotabi M. Hair analysis by means of laser induced breakdown spectroscopy technique and support vector machine model for diagnosing addiction. Iranian Journal of Physics Research. 2018;17(5):661-667. doi:10.29252/ijpr.17.5.661 
12. Bahreini M, Hosseinimakarem Z, Tavassoli SH. A study of association between fingernail elements and osteoporosis by laser-induced breakdown spectroscopy. J Appl Phys. 2012;112(5):054701. doi:10.1063/1.4747934

13. Shadman S, Bahreini M, Tavassoli SH. Comparison between elemental composition of human fingernails of healthy and opium-addicted subjects by laser-induced breakdown spectroscopy. Appl Opt. 2012;51(12):2004-2011. doi:10.1364/ ao.51.002004

14. Bahreini M, Tavassoli SH. Possibility of thyroidism diagnosis by laser induced breakdown spectroscopy of human fingernail. J Lasers Med Sci. 2012;3(3):127-31. doi:10.22037/2010.v3i3.3201

15. Bahreini M, Ashrafkhani B, Tavassoli SH. Discrimination of patients with diabetes mellitus and healthy subjects based on laser-induced breakdown spectroscopy of their fingernails. J Biomed Opt. 2013;18(10):107006. doi:10.1117/1. jbo.18.10.107006

16. Bahreini M, Ashrafkhani B, Tavassoli SH. Elemental analysis of fingernail of alcoholic and doping subjects by laser-induced breakdown spectroscopy. Appl Phys B. 2014;114(3):439-447. doi:10.1007/s00340-013-5538-7

17. Ashrafkhani B, Bahreini M, Tavassoli SH. Repeatability improvement of laser-induced breakdown spectroscopy using an auto-focus system. Opt Spectrosc. 2015;118(5):841846. doi:10.1134/s0030400x15050057

18. Riberdy VA, Frederickson CJ, Rehse SJ. Determination of the Zinc Concentration in Human Fingernails Using Laser-Induced Breakdown Spectroscopy. Appl Spectrosc. 2017;71(4):567-582. doi:10.1177/0003702816687568

19. Gazmeh M, Bahreini M, Tavassoli SH. Discrimination of healthy and carious teeth using laser-induced breakdown spectroscopy and partial least square discriminant analysis. Appl Opt. 2015;54(1):123-131. doi:10.1364/ao.54.000123

20. Gazmeh M, Bahreini M, Tavassoli SH, Asnaashari M. Qualitative analysis of teeth and evaluation of amalgam elements penetration into dental matrix using laser induced breakdown spectroscopy. J Lasers Med Sci. 2015;6(2):67-73.

21. Samek O, Telle HH, Beddows DC. Laser-induced breakdown spectroscopy: a tool for real-time, in vitro and in vivo identification of carious teeth. BMC Oral Health. 2001;1(1):1. doi:10.1186/1472-6831-1-1

22. de Menezes RF, Harvey CM, de Martinez Gerbi MEM, et al. Fs-laser ablation of teeth is temperature limited and provides information about the ablated components. J Biophotonics. 2017;10(10):1292-1304. doi:10.1002/jbio.201700042

23. Chen X, Li X, Yang S, Yu X, Liu A. Discrimination of lymphoma using laser-induced breakdown spectroscopy conducted on whole blood samples. Biomed Opt Express. 2018;9(3):1057-1068. doi:10.1364/boe.9.001057

24. Singh S, Badaya S. Laser induced breakdown spectroscopy (LIBS) for cervical cancer screening: The desired destination for the protracted hunt. J Cancer Policy. 2015;5:23-4. doi:10.1016/j.jcpo.2015.06.002

25. Teran-Hinojosa E, Sobral H, Sanchez-Perez C, Perez-Garcia A, Aleman-Garcia N, Hernandez-Ruiz J. Differentiation of fibrotic liver tissue using laser-induced breakdown spectroscopy. Biomed Opt Express. 2017;8(8):3816-3827. doi:10.1364/boe.8.003816

26. El-Hussein A, Kassem AK, Ismail H, Harith MA. Exploiting LIBS as a spectrochemical analytical technique in diagnosis of some types of human malignancies. Talanta. 2010;82(2):495501. doi:10.1016/j.talanta.2010.04.064

27. Cremers DA, Radziemski LJ. Handbook of Laser-Induced
Breakdown Spectroscopy. Chichester: Wiley; 2006.

28. Singh JP, Thakur SN. Laser-Induced Breakdown Spectroscopy. New York: Elsevier; 2007.

29. Aied Nassef O, Elsayed-Ali H. Spark discharge assisted laser induced breakdown spectroscopy. Spectrochim Acta Part B At Spectrosc. 2005;60(12):1564-1572. doi:10.1016/j. sab.2005.10.010

30. Li K, Zhou W, Shen Q, Ren Z, Peng B. Laser ablation assisted spark induced breakdown spectroscopy on soil samples. J Anal At Spectrom. 2010;25(9):1475-1481. doi:10.1039/ B922187E

31. Tereszchuk KA, Vadillo JM, Laserna JJ. Glow-dischargeassisted laser-induced breakdown spectroscopy: increased sensitivity in solid analysis. Appl Spectrosc. 2008;62(11):12621267. doi:10.1366/000370208786401491

32. Imam H, Mohamed R, Eldakrouri AA. Primary Study of the Use of Laser-Induced Plasma Spectroscopy for the Diagnosis of Breast Cancer. Opt Photonics J. 2012;2(3):193-9. doi:10.4236/opj.2012.23029

33. Miziolek AW, Palleschi V, Schechter I. Laser-induced breakdown spectroscopy (LIBS): fundamentals and applications. Cambridge: Cambridge University Press; 2006. doi:10.1017/CBO9780511541261

34. Abdel-Salam ZA, Galmed AH, Tognoni E, Harith MA. Estimation of calcified tissues hardness via calcium and magnesium ionic to atomic line intensity ratio in laser induced breakdown spectra. Spectrochim Acta Part B At Spectrosc. 2007;62(12):1343-1347. doi:10.1016/j.sab.2007.10.033

35. Kumar A, Yueh FY, Singh JP, Burgess S. Characterization of malignant tissue cells by laser-induced breakdown spectroscopy. Appl Opt. 2004;43(28):5399-5403.

36. EL Sherbini AM, Hagras MM, Farag HH, Rizk MRM. Diagnosis and classification of liver cancer using libs technique and artificial neural network. Int $J$ Sci Res. 2015;4(5):1153-1158.

37. Nasiadek M, Krawczyk T, Sapota A. Tissue levels of cadmium and trace elements in patients with myoma and uterine cancer. Hum Exp Toxicol. 2005;24(12):623-630. doi:10.1191/0960327105ht575oa

38. Nasiadek M, Kilanowicz A, Darago A, Lazarenkow A, Michalska M. The effect of cadmium on the coagulation and fibrinolytic system in women with uterine endometrial cancer and myoma. Int J Occup Med Environ Health. 2013;26(2):291301. doi:10.2478/s13382-013-0089-z

39. Rodriguez C, McCullough ML, Mondul AM, et al. Calcium, dairy products, and risk of prostate cancer in a prospective cohort of United States men. Cancer Epidemiol Biomarkers Prev. 2003;12(7):597-603.

40. Wysolmerski JJ, Broadus AE. Hypercalcemia of malignancy: the central role of parathyroid hormone-related protein. Annu Rev Med. 1994;45:189-200. doi:10.1146/annurev. med.45.1.189

41. Lokeshwar BL, Schwartz GG, Selzer MG, et al. Inhibition of prostate cancer metastasis in vivo: a comparison of 1,25-dihydroxyvitamin D (calcitriol) and EB1089. Cancer Epidemiol Biomarkers Prev. 1999;8(3):241-248.

42. Gupta SK, Shukla VK, Vaidya MP, Roy SK, Gupta S. Serum and tissue trace elements in colorectal cancer. J Surg Oncol. 1993;52(3):172-175.

43. Kohli GS, Bhargava A, Goel H, et al. Serum magnesium levels in patients with head and neck cancer. Magnesium. 1989;8(2):77-86

44. Tansy MF, Kendall MF. Mg and the gastrointestinal tract. Magnesium Bull. 1981;3:55-66. 